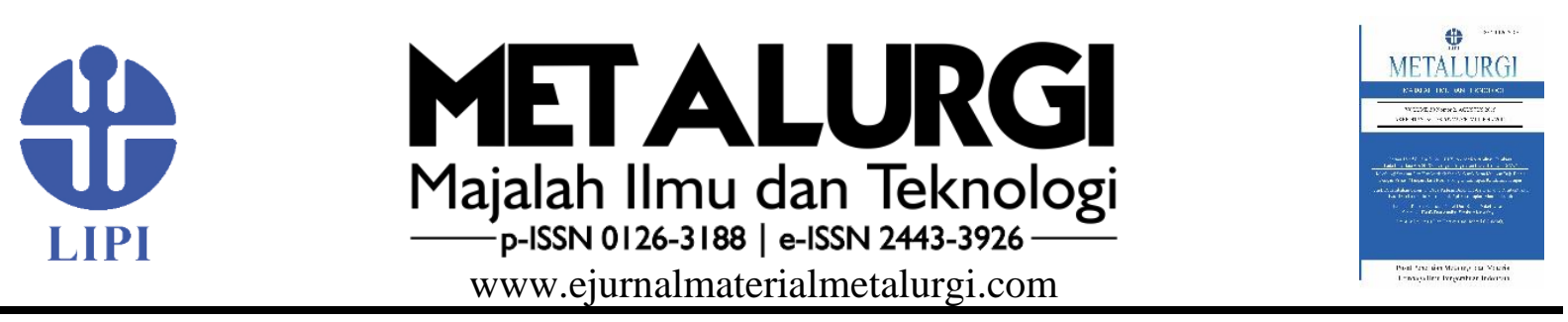

\title{
Pelindian ZirkoniUm dari Tailing MAgnetik Pasir Zirkon Hasil Roasting Menggunakan NaOH
}

\author{
Iga Trisnawati ${ }^{\mathrm{a}, \mathrm{b}^{*}}$, Gyan Prameswara ${ }^{\mathrm{a}}$, Kharistya Rozana ${ }^{\mathrm{b}}$, Himawan Tri Murti Bayu \\ Petrus $^{\text {a,c }}$, Agus Prasetya ${ }^{a, c}$, Panut Mulyono $^{a^{*}}$ \\ aDepartemen Teknik Kimia, UGM \\ Jl. Grafika No. 2, Kampus UGM, Yogyakarta, Indonesia 55281 \\ bPusat Sains dan Teknologi Akselerator, BATAN \\ Jl. Babarsari Kotak Pos 6101 ykbb Yogyakarta, 55281 \\ ${ }^{c}$ Unconventional Georesources Research Center, UGM \\ Jl. Grafika No. 2, Kampus UGM, Yogyakarta, Indonesia 55281 \\ *E-mail: trisnawati@batan.go.id,pmulyono@ugm.ac.id
}

Masuk Tanggal :04-06-2020, revisi tanggal:08-10-2020, diterima untuk diterbitkan tanggal : 26-12-2020

\begin{abstract}
Abstrak
Tailing pertambangan adalah penyebab sebagian besar pencemaran lingkungan yang terkait dengan industri ekstraktif. Peningkatan risiko pencemaran lingkungan telah diamati di seluruh dunia karena sejumlah besar pengolahan bijih kadar rendah. Dalam penelitian ini, pemulihan zirkonium dari tailing magnetik pasir zirkon telah diselidiki. Tujuan dari studi ini adalah untuk mengetahui pengaruh kondisi operasi pencucian terhadap pemulihan zirkonium dari tailing magnetik pasir zirkon. Tailing magnetik pasir zirkon yang digunakan dalam penelitian ini diperoleh dari PT Monokem Surya. Awalnya, tailing magnetik pasir zirkon dipanggang dengan tujuan memisahkan senyawa zirkonium dan silikat sebagai pengotor. Proses pemanggangan telah dilakukan dengan mereaksikan tailing magnetik zirkon pasir dan $\mathrm{NaOH}$ dengan perbandingan 1: 1 pada $450{ }^{\circ} \mathrm{C}$ selama 3 jam. Produk tersebut kemudian dicuci, dikeringkan dan dilindi menggunakan larutan $\mathrm{HCl}$ dan $\mathrm{H}_{2} \mathrm{SO}_{4}$. Untuk mengetahui kinerja pelindian, kondisi operasi bervariasi termasuk suhu $\left(30^{\circ} \mathrm{C}-110^{\circ} \mathrm{C}\right)$, konsentrasi asam $(0,125 \mathrm{M}-2 \mathrm{M})$ dan rasio padat terhadap cair $(0,05$ $\mathrm{g} / \mathrm{mL}-0,25 \mathrm{~g} / \mathrm{mL}$ ). Ditemukan bahwa pemulihan zirkonium mencapai optimal ketika proses pelindian menggunakan $0,5 \mathrm{M} \mathrm{HCl}$ dan $\mathrm{H}_{2} \mathrm{SO}_{4}$. Pada kondisi di atas menghasilkan pemulihan untuk zirkonium dengan $88 \% \mathrm{HCl}$ dan $26 \%$ $\mathrm{H}_{2} \mathrm{SO}_{4}$.
\end{abstract}

Kata Kunci: Pelindian, zirkon, tailing magnetik, pemanggangan

\begin{abstract}
Mine tailings are the cause of most environmental pollution associated with extractive industries. Increasing the risk of environmental pollution has been observed world-widely due to no small number of low-grade ore processing. In this study, the recovery of zirconium from zircon sand magnetic tailings has been investigated. The study aims to determine the effect of the operating conditions of leaching on the recovery of zirconium from magnetic sand tailings. The zircon sand magnetic tailings used in this analysis was obtained from Monokem Surya Ltd. Initially, zircon sand magnetic tailings were toasted with the intention of separating zirconium and silicate compounds as impurities. The roasting process was carried out with the reaction of zircon sand magnetic tailings and NaOH at a ratio of 1:1 at $450{ }^{\circ} \mathrm{C}$ for 3 hours. The commodity was then washed, dried, and washed using $\mathrm{HCl}$ and $\mathrm{H} 2 \mathrm{SO} 4$ solutions. The operating conditions, including temperature $\left(30{ }^{\circ} \mathrm{C}-110{ }^{\circ} \mathrm{C}\right)$, acid concentration $(0.125 \mathrm{M}-2 \mathrm{M})$ and solid to liquid ratio $(0.05 \mathrm{gr} / \mathrm{ml}-0.25 \mathrm{gr} / \mathrm{ml})$ were varied to determine the leaching efficiency. The recovery of zirconium was found to have reached its peak when $0.5 \mathrm{M}$ of $\mathrm{HCl}$ and $\mathrm{H}_{2} \mathrm{SO}_{4}$ were used in the leaching process. Recovery of $88 \%$ and $26 \%$ for zirconium was achieved using $\mathrm{HCl}$ and $\mathrm{H}_{2} \mathrm{SO}_{4}$, respectively.
\end{abstract}

Keywords: Leaching, zircon, magnetic tailing, roasting 


\section{Pendahuluan}

Tailing merupakan limbah yang dihasilkan oleh kegiatan tambang, dan kehadirannya dalam dunia pertambangan tidak bisa dihindari [1]. Sebagai limbah sisa pengolahan batuan-batuan yang mengandung mineral, tailing umumnya masih mengandung mineral-mineral berharga [2].

Pemrosesan mineral secara tradisional dapat menghasilkan tailing dalam jumlah besar dan deposit tailing ini harus menjadi perhatian serta penanganan dengan hati-hati [3]-[4]. Untuk mengurangi masalah tailing yang tidak terhindarkan ini, banyak teknik pemulihan tailing yang telah dilakukan, tetapi dengan hilangnya beberapa komponen yang berpotensi berharga [2], [5]. Sejauh ini kebanyakan tailing hanya disimpan dalam bendungan tailing setelah proses pengambilan mineral berharga dilakukan.

Mineral merupakan sumber daya yang tidak terbarukan, sehingga cadangan mineral dari tahun ke tahun jumlahnya semakin menurun, dan oleh karena itu bagaimana memaksimalkan pemanfaatan sumber daya mineral secara relevan telah mendapatkan perhatian lebih [2]. Daur ulang sumber sekunder memainkan peran yang semakin penting dalam hal ini [6]. Sebagai contoh, pemulihan logam-logam berharga (logam tanah jarang, niobium, besi dan titanium) dari tailing tambang telah menjadi area penelitian populer di beberapa tahun terakhir [2], [7]-[10]. Penggunaan kembali sumber daya sekunder memiliki tujuan yang sama yaitu memaksimalkan pemanfaatan sumber daya dan sementara itu mengurangi dampak yang berpotensi buruk terhadap lingkungan.

Dalam beberapa tahun terakhir, zirkonium dan paduannya menjadi semakin penting dan menarik untuk aplikasi yang luas [11]-[13]. Indonesia termasuk salah satu negara penghasil pasir zirkon dengan kontribusi sebesar 4\% [14]. Dikarenakan produksi yang terus menerus selama bertahun-tahun, maka diperoleh tailing dalam jumlah besar. Menanggapi hal tersebut, penggunaan kembali tailing semakin mendesak. Mineral zirkon $\left(\mathrm{ZrSiO}_{4}\right)$ kebanyakan berasosiasi dengan mineral berharga lain seperti monasit, senotim dan ilmenit [15]. Keuntungan mineral zirkon dilakukan melalui beberapa tahapan proses yaitu pemisahan berdasarkan perbedaan spesific gravity dilanjutkan dengan pemisahan berdasarkan perbedaan sifat kemagnetan mineral. Hasil pemisahan sifat kemagnetan mineral diperoleh mineral zirkon sebagai mineral non magnetik dan tailing magnetik berupa beberapa campuran mineral berharga [15].
Dalam penelitian ini, pemungutan zirkonium dari tailing magnetik pasir zirkon dipelajari secara terperinci. Zirkon mempunyai stabilitas yang tinggi $\left(\mathrm{dG}, 1400 \mathrm{~K}=-1498,1 \mathrm{kjmol}^{-1}\right)$ [16], sehingga dekomposisi zirkon membutuhkan suhu yang tinggi dan bahan kimia yang reaktif. Proses dekomposisi yang banyak digunakan melibatkan fusi kaustik zirkon dengan menggunakan kelebihan natrium hidroksida [17]. Natrium zirkonat terbentuk bersama dengan natrium silikat, dan semua produk hasil dekomposisi ditambahkan air untuk melarutkan natrium silikat dan menghidrolisis natrium zirkonat membentuk $\mathrm{Zr}(\mathrm{OH})_{4}$ [16]. Hidroksida yang terbentuk kemudian dapat disaring dan dikalsinasi $\mathrm{ke} \mathrm{ZrO}_{2}$ atau diolah dengan asam untuk diproses lebih lanjut menjadi senyawa lain.

Karena terbatasnya informasi yang tersedia dalam literatur tentang pemulihan zirkonium dari tailing magnetik pasir zirkon, maka penelitian yang kami lakukan bertujuan untuk menyelidiki kondisi optimum dari pelindian zirkonium dalam asam menggunakan tailing magneti pasir zirkon sebagai bahan baku sekunder. Studi ini diharapkan dapat berkontribusi pada pemahaman yang lebih baik tentang pelindian zirkonium tidak hanya dari tailing magnetik pasir zirkon tetapi juga dari berbagai tailing mineral yang mengandung zirkonium.

\section{Prosedur Percobahn}

\subsection{Material}

Tailing pasir zirkon yang digunakan dalam penelitian ini berasal dari PT Monokem Surya. Komposisi kimia dianalisis menggunakan XRF ( $x$-ray fluorescence) dan ditunjukkan pada Tabel 1. Analisis XRD (x-ray diffraction) sampel magnetik tailing pasir zirkon dilakukan menggunakan instrumen PANalytical Aeris Research DY 844. $\mathrm{NaOH}$ dan $\mathrm{H}_{2} \mathrm{SO}_{4}$ analitik digunakan dalam seluruh percobaan ini.

\subsection{Prosedur Penelitian}

Tailing magnetik pasir zirkon dengan ukuran -120 mesh dipanggang dengan $\mathrm{NaOH}$ pada suhu $450{ }^{\circ} \mathrm{C}$ selama 3 jam dalam sebuah tungku. Rasio massa $\mathrm{NaOH}$ dengan tailing magnetik pasir zirkon adalah 1:1. Produk pemanggangan dicuci dengan air suling panas dalam kondisi operasi: $80{ }^{\circ} \mathrm{C}, 1 \mathrm{jam}$, rasio cairan-padatan $10 \mathrm{~mL} / \mathrm{g}$. Setelah selesai, larutan dipisahkan dengan cepat dengan filtrasi vakum. Hasil padatan dari tahap pencucian dikeringkan di dalam oven. Padatan hasil pencucian yang telah kering digunakan sebagai umpan leaching menggunakan $\mathrm{H}_{2} \mathrm{SO}_{4}$ dan $\mathrm{HCl}$. Dalam percobaan ini leaching dipelajari 
dengan teknik batch dengan waktu reaksi selama $1 \mathrm{jam}$, konsentrasi asam bervariasi antara $0,125 \mathrm{M}$ dan $2 \mathrm{M}$, perbandingan padatan/cairan bervariasi antara 0,05 dan $0,25(\mathrm{~g} / \mathrm{mL})$ dan suhu bervariasi antara suhu kamar dan $110^{\circ} \mathrm{C}$. Pada akhir tiap tes, padatan sisa leaching dianalisis untuk mengetahui sisa zirkon yang tidak sempurna saat proses leaching menggunakan XRF Epsilon 4. Persentase leaching (L,\%) dari zirkon dapat dihitung sebagai persamaan (1).

$$
L(\%)=\frac{c_{0}-C_{1}}{c_{0}} \times 100 \%
$$

Dimana $\mathrm{C}_{0}$ adalah konsentrasi zirkon fase padat awal, dan $\mathrm{C}_{1}$ adalah konsentrasi zirkon fase padat sisa leaching.

\section{Hasil dan Pembahasan}

\subsection{Karakterisasi Mineralogi dari Tailing Magnetik Pasir Zirkon}

Xenotime dikonfirmasi sebagai fase utama dalam pasir zirkon dari hasil XRD ( $x$-ray diffraction). Selain xenotime, monasit, zirkon, anatase, rutile dan cerianite juga terdapat dalam mineral tailing pasir zirkon. Rincian masingmasing mineral disajikan pada Gambar 1.

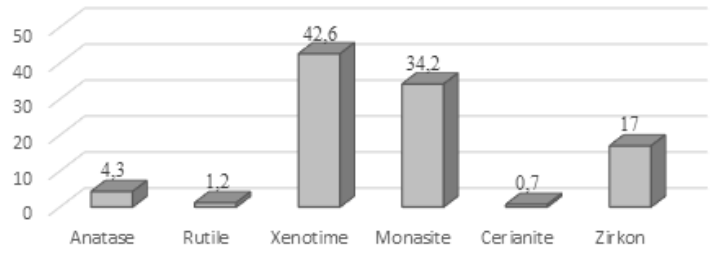

Gambar 1. Presentase berbagai mineral dalam tailing magnetic pasir zirkon

\subsection{Pelindian Zirkonium}

Produk alkali fusi yang tidak larut, yang diperoleh dari hasil pelindian sebelumnya menggunakan air terdiri dari natrium zirkonat, zirkon oksida terhidrasi, natrium silikat residu, asam silikat, sisa mineral zirkon yang merupakan reaksi antara mineral zirkon yang terdapat pada tailing magnetik dengan $\mathrm{NaOH}$ [17]. Sedangkan untuk mineral logam tanah jarang (monasit dan xenotim), produk alkali fusi yang tidak larut berupa logam tanah jarang hidroksida [18]-[19]. Untuk mineral titanium dalam bentuk rutil dan anatase, produk hasil alkali fusi yang tidak larut berupa natrium titanat [20]-[21].

Reaksi senyawa zirkon dan silikon yang merupakan hasil dari produk alkali fusi mineral zirkon dalam $\mathrm{H}_{2} \mathrm{SO}_{4}$ dan $\mathrm{HCl}$ dapat diwakili oleh reaksi kimia (1) dan (2) [17], [22]

$$
\begin{aligned}
& \mathrm{Na}_{2} \mathrm{ZrO}_{3}+2 \mathrm{H}_{2} \mathrm{SO}_{4} \rightarrow \mathrm{ZrO}(\mathrm{SO})_{4}+\mathrm{Na}_{2} \mathrm{SO}_{4}+2 \mathrm{H}_{2} \mathrm{O} \\
& \mathrm{Na}_{2} \mathrm{ZrO}_{3}+2 \mathrm{HCl} \rightarrow \mathrm{ZrOCl}_{2}+\mathrm{H}_{2} \mathrm{O}
\end{aligned}
$$

\subsubsection{Pengaruh Suhu}

Suhu merupakan parameter yang penting dalam menentukan kondisi pelindian yang optimum. Pelindian dilakukan dalam kisaran suhu ruang hingga $110{ }^{\circ} \mathrm{C}$ untuk konsentrasi asam $2 \mathrm{M}$. Gambar 2 menyajikan pengaruh suhu pada pelindian zirkon menggunakan $\mathrm{HCl}$ dan $\mathrm{H}_{2} \mathrm{SO}_{4}$. Perubahan suhu dari suhu ruangan menjadi $100{ }^{\circ} \mathrm{C}$ meningkatkan pemungutan zirkonium dari $13 \%$ menjadi $24 \%$ untuk reagen pelindian $\mathrm{H}_{2} \mathrm{SO}_{4}$. Sedangkan untuk reagen pelindian $\mathrm{HCl}$, pemungutan zirkonium meningkat menjadi 44\%. Meningkatkan suhu lebih lanjut dalam proses pelindian akan menurunkan hasil pemungutan zirkonium [16], hal ini mungkin disebabkan karena terjadinya presipitasi oksida hidro dari zirkonium [23]. Fenomena yang sama juga diamati pada logam transisi lain seperti nikel [24] dan titanium [16].

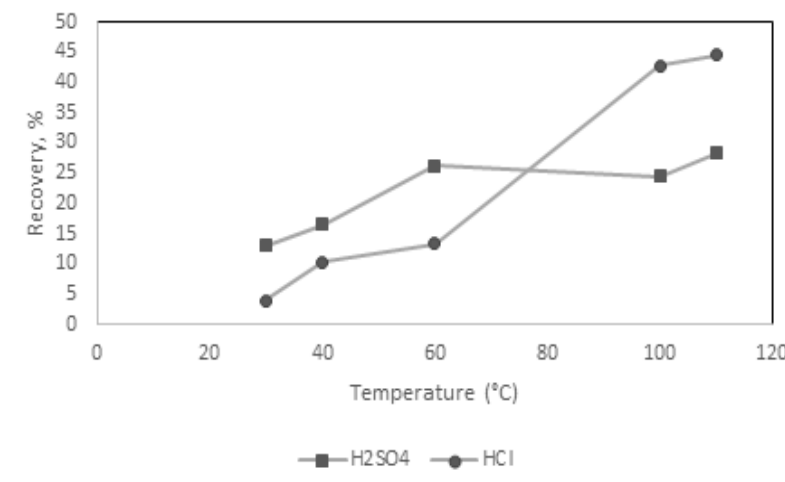

Gambar 2. Pengaruh suhu pada pelindian menggunakan $\mathrm{HCl}$ dan $\mathrm{H}_{2} \mathrm{SO}_{4}$

\subsubsection{Pengaruh Konsentrasi}

Konsentrasi asam sebagai reagen pelindi merupakan parameter yang sangat berpengaruh dalam proses pelindian mineral [25]. Pengaruh konsentrasi asam terhadap hasil recovery zirkon dipelajari pada rentang konsentrasi asam antara $0,125 \mathrm{M}-2 \mathrm{M}$ pada suhu $80^{\circ} \mathrm{C}$. Penggunaan $\mathrm{HCl}$ dan $\mathrm{H}_{2} \mathrm{SO}_{4}$ sebagai reagen pelindi juga dibandingkan dalam penelitian ini. Hasil yang diperoleh untuk pemungutan $\mathrm{Zr}$ ( $\mathrm{Zr}$ recovery) karena pengaruh konsentrasi asam menggunakan $\mathrm{HCl}$ dan $\mathrm{H}_{2} \mathrm{SO}_{4}$ dapat dilihat pada Gambar 3. Pemungutan zirkon meningkat seiring dengan kenaikan konsentrasi asam pada pelindian menggunakan $\mathrm{H}_{2} \mathrm{SO}_{4}$. Meningkatkan konsentrasi asam dari $0,125 \mathrm{M}$ menjadi $2 \mathrm{M}$, pemungutan zirkonium meningkat dari $14 \%$ menjadi $22 \%$. Hal ini dikarenakan peningkatan konsentrasi reaktan meningkatkan laju kecepatan reaksi pelindian [16]. Namun hal serupa tidak berlaku untuk pemungutan zirkonium mengunakan $\mathrm{HCl}$. Dengan meningkatkan konsentrasi asam pemungutan zirkonium cenderung semakin turun, 
hal ini dapat dikaitkan dengan pembentukan silika (aspek gel). Gel ini mengganggu proses filtrasi dan dapat dihindari dengan menggunakan konsentrasi $\mathrm{HCl}$ yang rendah selama proses pelindian zirkonium menggunakan $\mathrm{HCl}$ [17]. Selain itu $\mathrm{HCl}$ lebih selektif terhadap senyawasenyawa lain hasil produk alkali fusi (Ti dan logam tanah jarang) dibandingkan dengan $\mathrm{Zr}$. Dari penelitian Prameswara, dkk., [19], [26] pemungutan senyawa Ti dan logam tanah jarang memiliki kecenderungan meningkat dengan meningkatnya konsentrasi $\mathrm{HCl}$.

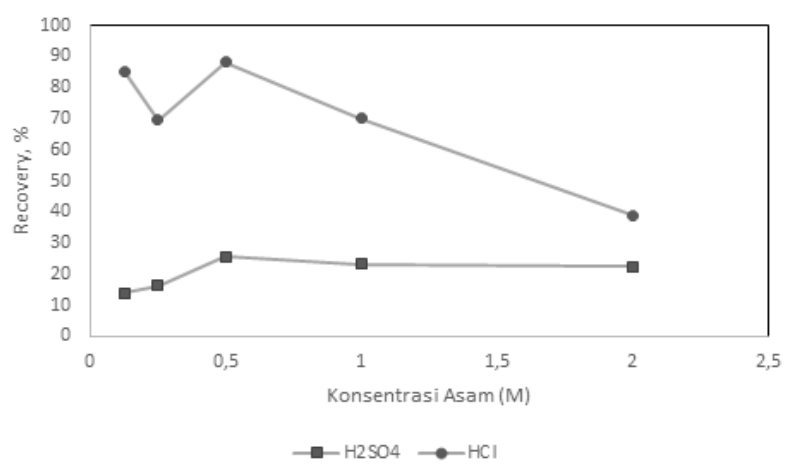

Gambar 3. Pengaruh konsentrasi $\mathrm{HCl}$ dan $\mathrm{H}_{2} \mathrm{SO}_{4}$ pada pelindian zirkonium suhu $80^{\circ} \mathrm{C}$

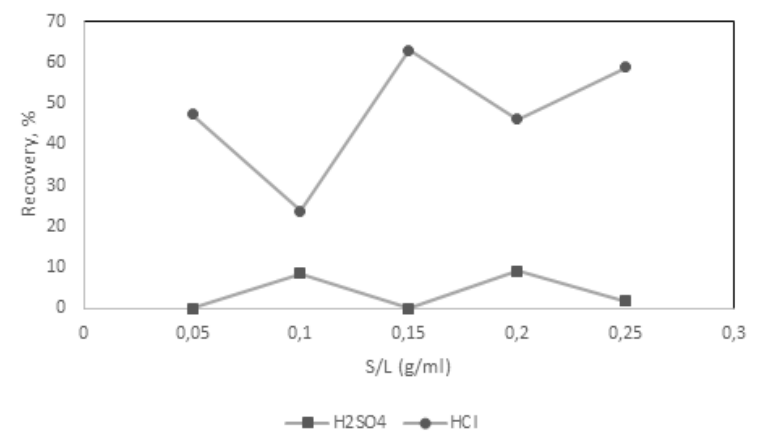

Gambar 4. Pengaruh rasio padat-cair pada pelindian zirkonium menggunakan $\mathrm{H}_{2} \mathrm{SO}_{4}$ dan $\mathrm{HCl}$

\subsubsection{Pengaruh Padatan/Cairan}

Efek rasio padat cair dalam kisaran 0,05 $0,25 \mathrm{~g} / \mathrm{ml}$ telah dipelajari pada $80^{\circ} \mathrm{C}$, konsentrasi asam awal $2 \mathrm{M}$ dan waktu pelindian 60 menit. Dalam reaksi kimia cair dan padat, rasio cairpadatan merupakan salah satu faktor penting. Diketahui bahwa rasio padatan dengan cairan yang lebih rendah dapat mengurangi viskositas campuran sehingga dapat meningkatkan laju perpindahan massa antara padatan dan cairan [27]. Gambar 4 menyajikan pengaruh rasio padatan-cairan pada pelindian zirkonium menggunakan $\mathrm{H}_{2} \mathrm{SO}_{4}$ dan $\mathrm{HCl}$. Hasil menunjukkan bahwa tidak terjadi peningkatan nilai pemungutan secara signifikan untuk rasio padatan - cairan yang berbeda. Hasil ekstraksi zirkonium ini menunjukkan bahwa difusi eksternal reagen pelindian dapat memenuhi kebutuhan reaksi pelindian di bawah rasio cairanpadatan ini. Sehingga dapat disimpulkan bahwa proses pelindian zirkonium dikendalikan oleh difusi internal atau laju reaksi kimia [27]. Dari hasil pelindian zirkonium menggunakan $\mathrm{HCl}$ atau $\mathrm{H}_{2} \mathrm{SO}_{4}$, hasil pelindian maksimum mencapai $63 \%$.

\section{KeSimpUlan}

Dari hasil percobaan dapat diperoleh kesimpulan bahwa konsentrasi asam, perbandingan padatan dan cairan serta suhu berpengaruh terhadap proses pelindian. Semakin tinggi konsentrasi asam yang digunakan, mengakibatkan presentase pemungutan zirkonium semakin menurun. Hal ini disebabkan karena terbentuknya gel silika yang mengganggu proses filtrasi, sehingga menambah jumlah residu dalam proses pelindian. $\mathrm{HCl}$ memberikan hasil yang lebih baik sebagai reagen pelindi dibandingkan dengan $\mathrm{H}_{2} \mathrm{SO}_{4}$. Kondisi optimum proses pelindian diperoleh dengan reagen pelindi berupa $\mathrm{HCl}$ dengan konsentrasi sebesar $0,5 \mathrm{M}$, perbandingan padatan dan cairan $0,15 \mathrm{~g} / \mathrm{mL}$, dan suhu operasi pada $100{ }^{\circ} \mathrm{C}$.

\section{UCAPAN TERIMA KASIH}

Penulis mengucapkan terima kasih kepada Direktorat Riset dan Pengabdian Masyarakat, Direktorat Jendral Penguatan Riset dan Pengembangan, Kementrian Riset, Teknologi dan Pendidikan Tinggi yang telah memberikan bantuan dana penelitian dalam program PDD (2898/UN1.DITLIT/DIT-LIT/LT/2019). Iga Trisnawati menghargai dukungan keuangan dari Beasiswa Saintek-Kemenristek/BRIN

\section{Daftar Pustaka}

[1] E. Schoenberger, "Environmentally sustainable mining: The case of tailings storage facilities," Resour. Policy, vol. 49, pp. 119-128, 2016.

[2] J. Zhai, H. Wang, P. Chen, Y. Hu, dan W. Sun, "Recycling of iron and titanium resources from early tailings: From fundamental work to industrial application," Chemosphere, vol. 242, pp. 125178, 2020.

[3] Z. Bian, X. Miao, S. Lei, S. E. Chen, W. Wang, dan S. Struthers, "The challenges of reusing mining and mineral-processing wastes," Science, vol. 337, no. 6095, pp. 702-703, 2012.

[4] L. Wang, B. Ji, Y. Hu, R. Liu, dan W. Sun, "A review on in situ phytoremediation of mine tailings," Chemosphere, vol. 184, pp. 
594-600, 2017.

[5] M. J. Khan dan D. L. Jones, "Effect of composts, lime and diammonium phosphate on the phytoavailability of heavy metals in a copper mine tailing soil," Pedosph. An Int. J., vol. 19, no. 5, pp. 631-641, 2009.

[6] L. Raghupathy dan A. Chaturvedi, "Secondary resources and recycling in developing economies," Sci. Total Environ., vol. 461-462, pp. 830-834, 2013.

[7] X. Lyu, G. Yao, Z. Wang, Q. Wang, dan L. Li, "'Hydration kinetics and properties of cement blended with mechanically activated gold mine tailings," Thermochim. Acta, vol. 683, pp. 178457, 2020.

[8] B. Bagheri, J. Vazifeh Mehrabani, dan S. Farrokhpay, "Recovery of sphalerite from a high zinc grade tailing," J. Hazard. Mater., vol. 381, pp. 120946, 2020.

[9] G. T. Munive, M. A. Encinas, M. M. Salazar Campoy, V. E. Álvarez, V. M. Vazquez, dan D. C. Choque, "Leaching gold and silver with an alternative system, glycine: Thiosulfate from mineral tailings," Jom, 2019. DOI : 10.1007/s11837-019-03652-z.

[10] X. L. Yu, L. Bai, Q. C. Wang, J. Liu, M. Y. Chi, dan Z. C. Wang, "Recovery of rare earths, niobium, and thorium from the tailings of giant bayan obo ore in china," Metall. Mater. Trans. B, vol. 43, no. 3, pp. 485-493, 2012.

[11] C. H. V. G. K. Murty, R. Upadhyay, dan S. Asokan, "Recovery of zircon from Sattankulam deposit in India-problems and prospects," 6th Int. Heavy Miner. Conf. 'Back to Basics', pp. 69-74, 2007.

[12] R. K. Biswas, M. A. Habib, A. K. Karmakar, dan M. R. Islam, "A novel method for processing of Bangladeshi zircon: Part I: Baking, and fusion with $\mathrm{NaOH}$," Hydrometallurgy, vol. 103, no. 1-4, pp. 124-129, 2010.

[13] S. Srikanth, V. L. Devi, dan R. Kumar, "Unfolding the complexities of mechanical activation assisted alkali leaching of zircon ( $\mathrm{ZrSiO} 4)$," Hydrometallurgy, vol. 165, pp. 125-136, 2016.

[14] T. Suseno, "Analisis prospek pasir zirkon Indonesia di pasar dunia," Teknol. Miner. dan Batubara, vol. 11, no. 1, pp. 61-77, 2015.

[15] H. Poernomo, D. Biyantoro, dan M. V.
Purwani, "Kajian konsep teknologi pengolahan pasir zirkon lokal yang mengandung monasit, senotim, dan ilmenit," Eksplorium, vol. 37, no. 2, pp. 73-88, 2016.

[16] T. Makanyire, A. Jha, dan S. Sutcliffe, "A kinetic analysis of acid leaching of niobium and zirconium from titania waste residue stream: An energy efficient methodology for the reclamation of metal values," Energy Technol. 2015 Carbon Dioxide Manag. Other Technol., pp. 115122, 2016

[17] R. J. F. Da Silva, A. J. B. Dutra, dan J. C. Afonso, "Alkali fusion followed by a twostep leaching of a Brazilian zircon concentrate," Hydrometallurgy, vol. 117118, pp. 93-100, 2012.

[18] I. Trisnawati, G. Prameswara, P. Mulyono, A. Prasetya, dan H. T. B. M. Petrus, "Sulfuric acid leaching of heavy rare earth elements (HREEs) from Indonesian zircon tailing," Int. J. Technol., vol. 11, no. 4, pp. 804-816, 2020.

[19] G. Prameswara, I. Trisnawati, H. Poernomo, P. Mulyono, A. Prasetya, dan H. T. B. M. Petrus, "Kinetics of yttrium dissolution from alkaline fusion on zircon tailings," Mining, Metall. Explor., vol. 37, no. 4, pp. 1297-1305, 2020.

[20] R. Subagja, A. Royani, dan P. Prasetyo, "Pengaruh penambahan $\mathrm{NaOH}$, temperatur dan waktu terhadap pembentukan fasa natrium titanat dan natrium ferit pada proses pemanggangan ilmenit Bangka," Metalurgi, vol. 27, pp. 241-249, 2012.

[21] A. Sari, J. Kimia, F. Matematika, dan P. Alam, "Studi pengaruh dekomposisi pasir besi dengan $\mathrm{NaOH}$ terhadap pemisahan titanium," J. Sains dan Seni Pomits, pp. 0-6, 2003.

[22] R. K. Biswas, M. A. Habib, dan M. R. Islam, "A novel method for processing of Bangladeshi zircon: Part II: Leaching of zircon-caustic fused mass by hydrochloric acid," Hydrometallurgy, vol. 103, no. 1-4, pp. 130-135, 2010.

[23] G. L. J. P. da Silva, M. L. C. P. da Silva, dan T. Caetano, "Preparation and characterization of hydrous zirconium oxide formed by homogeneous precipitation," Mater. Res., vol. 5, no. 2, pp. 149-153, 2002.

[24] A. S. Madeja, "Kinetics of Mo, Ni, V and $\mathrm{Al}$ leaching from a spent hydrodesulphurization catalyst in a 
solution containing oxalic acid and hydrogen peroxide," J. Hazard. Mater., vol. 186, no. 2-3, pp. 2157-2161, 2011.

[25] H. S. E. A. Gustiana, I. M. Bendiyasa, H. T. B. M. Petrus, F. R. Mufakhir, dan W. Astuti, "Pelindian nikel dari bijih limonit low-grade Pomalaa menggunakan pelarut asam asetat," Prosiding Seminar Nasional Teknik Kimia Kejuangan, pp. 1-7, 2018.

[26] G. Prameswara, P. Mulyono, A. Prasetya, H. Poernomo, dan I. Trisnawati, "Ekstraksi logam tanah jarang (LTJ) dan logam berharga hasil fusi alkali tailing zirkon," Prosiding Seminar Nasional Teknik Kimia Kejuangan, pp. 1-7, 2019.

[27] Y. Huang, Z. Dou, T. Zhang, dan J. Liu, "Leaching kinetics of rare earth elements and fluoride from mixed rare earth concentrate after roasting with calcium hydroxide and sodium hydroxide," Hydrometallurgy, vol. 173, pp. 15-21, 2017. 